\title{
Message Gateway-Based Control System for Parents on the use of Motorcycle Vehicles in Young Adolescents
}

\author{
Nanda Tommy Wirawan, S.Kom, M.Kom ${ }^{1}$ \\ Universitas Putra Indonesia "YPTK” Padang \\ Jl. Raya Lubuk Begalung Padang \\ Sumatera Barat \\ Email : nandatommyw@upiyptk.ac.id
}

\author{
Sepsa Nur Rahman, S.Kom, M.Kom ${ }^{2}$ \\ Universitas Putra Indonesia "YPTK" Padang \\ Jl. Raya Lubuk Begalung Padang \\ Sumatera Barat \\ Email : sepsanurrahman@upiyptk.ac.id
}

\begin{abstract}
Given the large number of fatalities and the amount of economic and social losses caused by road accidents, it is necessary to build a road safety culture early on in Indonesia. Various programs and socialization efforts have been carried out to reduce the high number of accidents. One of the socialization steps is the concept of introducing SMS gateway surveillance for parents to be able to supervise the use of vehicles by young teenagers. The concept of notification in the form of an SMS gateway is more specifically devoted to motorbike riders for teenagers who are only able to drive on public roads, bearing in mind young teenagers are often reckless then it is the biggest contributor to accidents in Indonesia. This research is focused on the problem of means of use and supervision in driving, especially for parental supervision of young teenagers. Using this system will reduce road accidents, because young teenagers will be monitored by this system and notified their parents to take further action against vehicle users. This form of system works if the driver crosses the normal speed of driving, the system will automatically send sms to the parents of the children who are driving, the parents' supervision of the child in driving increases so that the level of traffic accidents will decrease, and parents can find out where their child is.
\end{abstract}

Keywords : Arduino, SMS Gateway, GPS, Sensor

\section{INTRODUCTION}

Road safety is very important to be considered by every road user. There are various traffic signs that are installed either on the markers or on the road, all of which are intended to bring order to road users, and directly aim to maintain the safety of road users. However, most of the way to drive Indonesian people tend to be bad, the rules (signs) on the highway they break a lot. Cases of traffic violations on the road by road users tend to result in accidents, indiscipline of road users and traffic congestion that is felt to be increasing.

Learning aggressive driving behavior is important for a number of reasons. First, from a safety standpoint, aggressiveness has proven to be a major cause of traffic accidents. Aggressive driving is manifested through a combination of intentional or unsafe traffic violations driving behaviors such as running red lights, road markings, overtaking This is because the lack of public awareness to obey traffic rules is the frequent occurrence of fatal accidents. Concerns about road safety are seen as a major public health problem despite the availability of sophisticated management techniques to curb traffic hazards. Driving anger, impulsiveness, and instrumental and emotional aggressiveness have been proposed as three aggressive predictors and transgressively driving behavior. and instrumental and emotional aggressiveness have been proposed as three aggressive predictors and transgressively driving behavior.

Based on the background of the problems above, then the problem formulation 
appears, "Can we prevent or reduce the occurrence of accidents, especially for motorcycle riders whose children are driving so that they don't drive too fast?" Based on the formulation of the problem, the researcher is interested in testing more information about the safety of motorcyclists by taking the title of the study "Gateway-Based Supervision System for Parents Against the Use of Motorcycle Vehicles in Young Adolescents"

\section{LITERATURE REVIEW}

\subsection{Basic Concepts of the System}

The system is a network of interrelated procedures, gathered together to carry out an activity or to complete a specific goal. The system generally has the input needed to be processed and will produce output or output in the form of information.

\subsection{SMS Gateway}

SMS (Short Message Service) is a technology that allows to send and receive messages between mobile phone users. Sms Gateway is a platform that provides a mechanism for EUA to deliver and receive SMS from mobile devices (cellphones, phones, etc.) via SMS Gateway's shortcode. SMS gateway is an application system for sending and / or receiving SMS, mainly used in business applications, both for promotional purposes, service to customers, procurement of product or service content, and so on.

\subsection{Arduino Uno}

Arduino Uno is a microcontroller board based on ATmega328. Arduino Uno has 14 digital input / output pins (6 of which can be used as PWM outputs), 6 analog inputs, a $16 \mathrm{MHz}$ Crystal oscillator, a USB connection, a power jack, a ICSP header and a reset button. Arduino Uno contains everything needed to support a microcontroller, easily connect it to a computer with a USB cable or supply it with an AC to DC adapter or use a battery to start it (Ruri and Surmayanti, 2016).

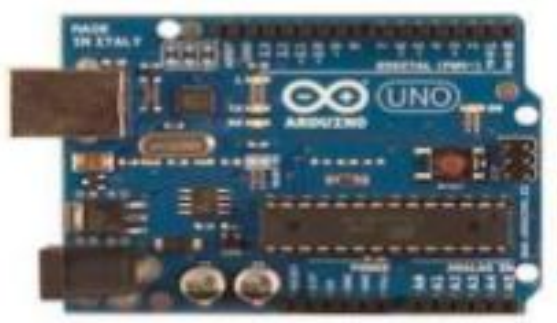

\subsection{GPS (Global Positioning System)}

GPS (Global Positioning System) is a navigation system based on interconnected satellites in orbit. The satellites belong to the United States Department of Defense which were first introduced in 1978 and in 1994 used 24 satellites. GPS is the only global navigation satellite system for determining location, speed, direction, and time that has operated fully in the world today (undergraduate thesis Wildan Habibi, ITS, Surabaya January: 2011).

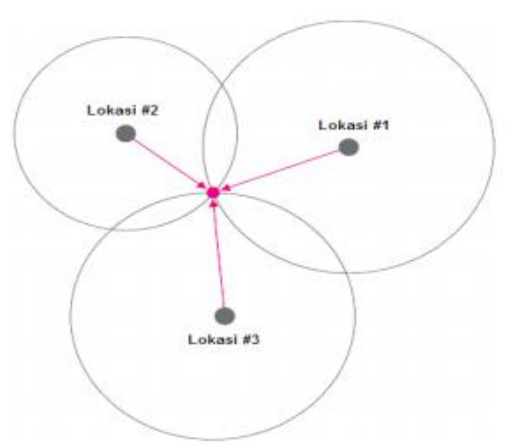

Figure 2. of Trilateration in Global Positioning System (GPS)

\section{RESEARCH METHOD}

This framework is the steps that will be carried out in order to solve the problem that will be discussed, such as Figure 3: 


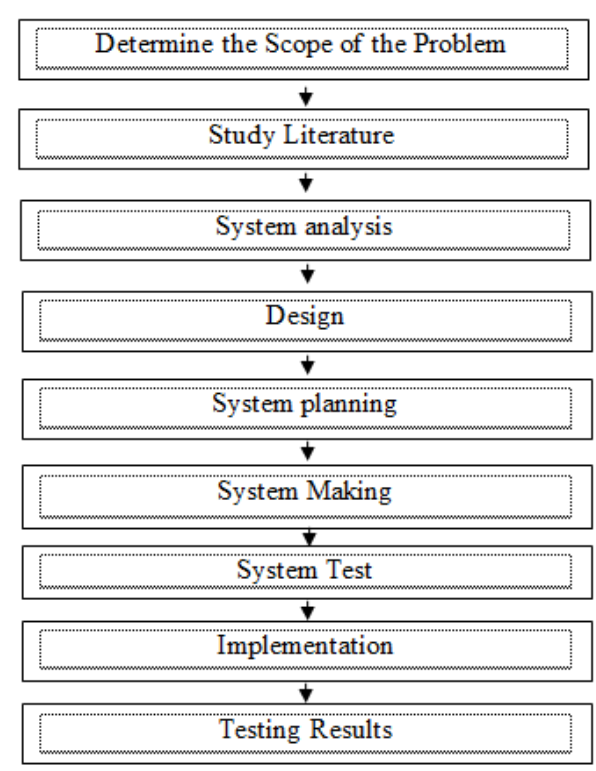

Figure 3. Research Methodology

Based on the framework, each step can be described as follows:

1. Defining the Scope of the Problem

The problem space to be investigated must be determined in advance, because without being able to define and determine the boundaries of the problem to be studied, then the best solution of the problem will not be found.

1. Notification system in the form of SMS Gateway to parents can prevent and minimize traffic accidents

2. Parents can find out or supervise their children in driving speed

3. GPS technology as a medium in knowing the position of a child who is riding a motorcycle.

\section{Study Literature}

To achieve the objectives to be determined, it is necessary to study some of the literature used. Then the literature studied is selected to determine which literature will be used in research. Through literature studies, theories are related to Optocoupler, GPS, GSM Modules, and application of technology. Literature sources in the form of books, journals, and data from internet sites in accordance with research.

\section{System Analysis}

At this stage, which is analyzing all matters related to the design of the Gateway Sms-Based Monitoring System for Parents Against the Use of Motorcycle Vehicles in Young Adolescents. The things analyzed are as follows:

a. Optocoupler sensor that functions as an input;

b. The components that help control the process;

c. The use of GPS as a medium to find out the coordinates of the location;

d. Hardware and Software used.

4. System Design

At the design stage, it is determined which elements are contained which will be poured into the flowchart. Flowchart is a reference flow in the manufacture of sms gateway-based surveillance systems.

\section{System Design}

This stage aims to design a system that will be created, such as:

a. SMS gateway based surveillance system design;

b. Electronic circuit design in the learning system;

c. Program design.

6. System Making

At this stage, what is made is:

a. Making Miniature made from acrylic base with a size of $15 \mathrm{~cm}$ x $10 \mathrm{~cm}$;

b. Making of a Control System.

7. Test the System

At this stage, the system to be tested is:

a. Supervision system that has integrated GSM and GPS modules;

b. Output Interaction in the form of Relay.

Testing the system uses Arduino software for programming with the help of a downloader tool that is used to fill the program into the Arduino microcontroller. Then each module is tested whether it is functioning or not.

8. Implementation

At this stage, the implementation of optocoupler sensors, GPS, and GSM modules so that the system can read and 
process data that will be sent to the control system in order to provide information as an interaction with parents.

9. Testing Results

At this stage, the system tests whether the data read on the optocoupler and GPS sensors match the information provided to parents.

Tested at this stage are:

1. Optocoupler Sensor;

2. GSM Module;

3. GPS.

\section{RESULTS AND DISCUSSION}

\subsection{System Design in General}

In general, the form of a Sms Gateway Based Monitoring System for Parents Against the Use of Motorcycle Vehicles in Young Adolescents is described by using a Context Diagram and Data Flow Diagrams.

\subsection{Context Diagram}

In this section, Context diagrams are used to facilitate the process of analyzing the system as a whole. In this case the Context Diagram functions as a media, which consists of a process and several external entities. Context diagram of the system can be seen in Figure 4.

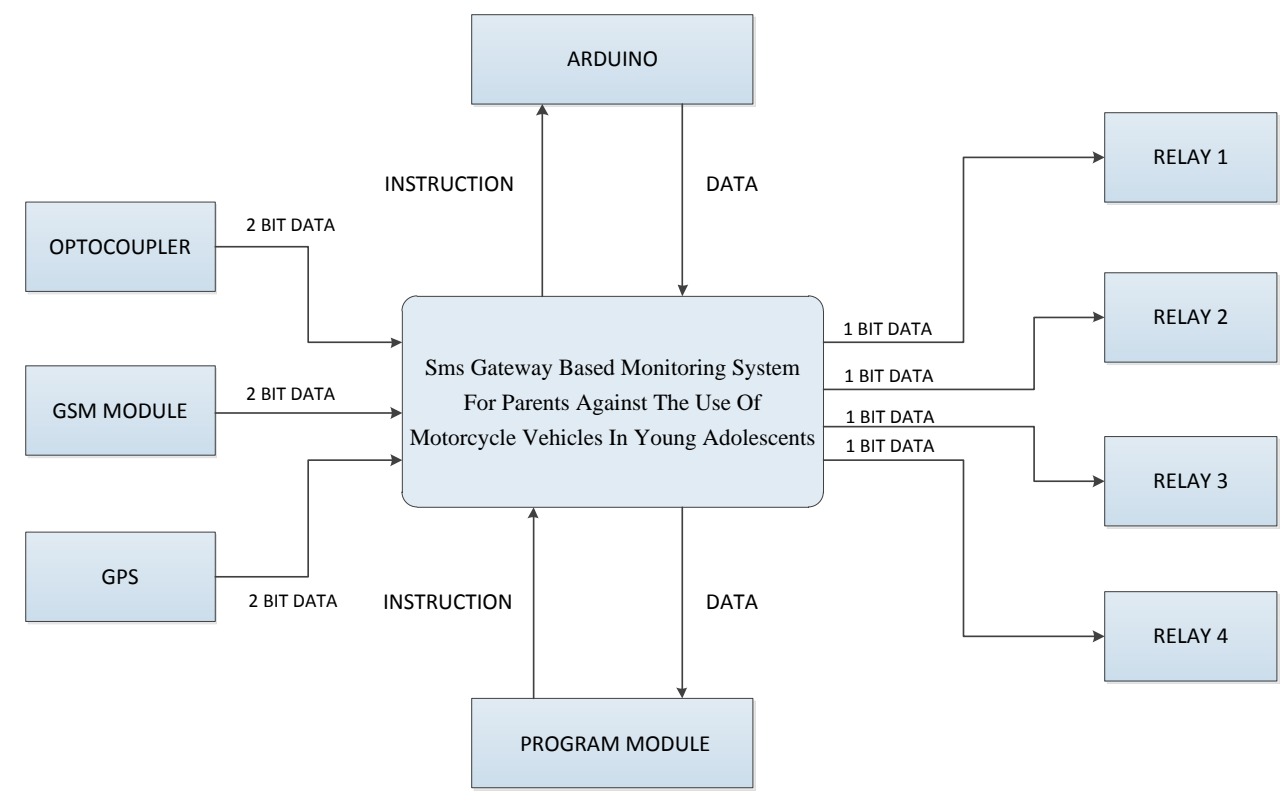

Figure 4. Context Diagram

\subsection{Data Flow Diagrams}

Data Flow Diagrams are a more detailed picture of the system created. Data Flow Diagrams used are Data Flow Diagrams level 0 because only one system has been developed. Data Flow Diagrams can be seen in Figure 5. 


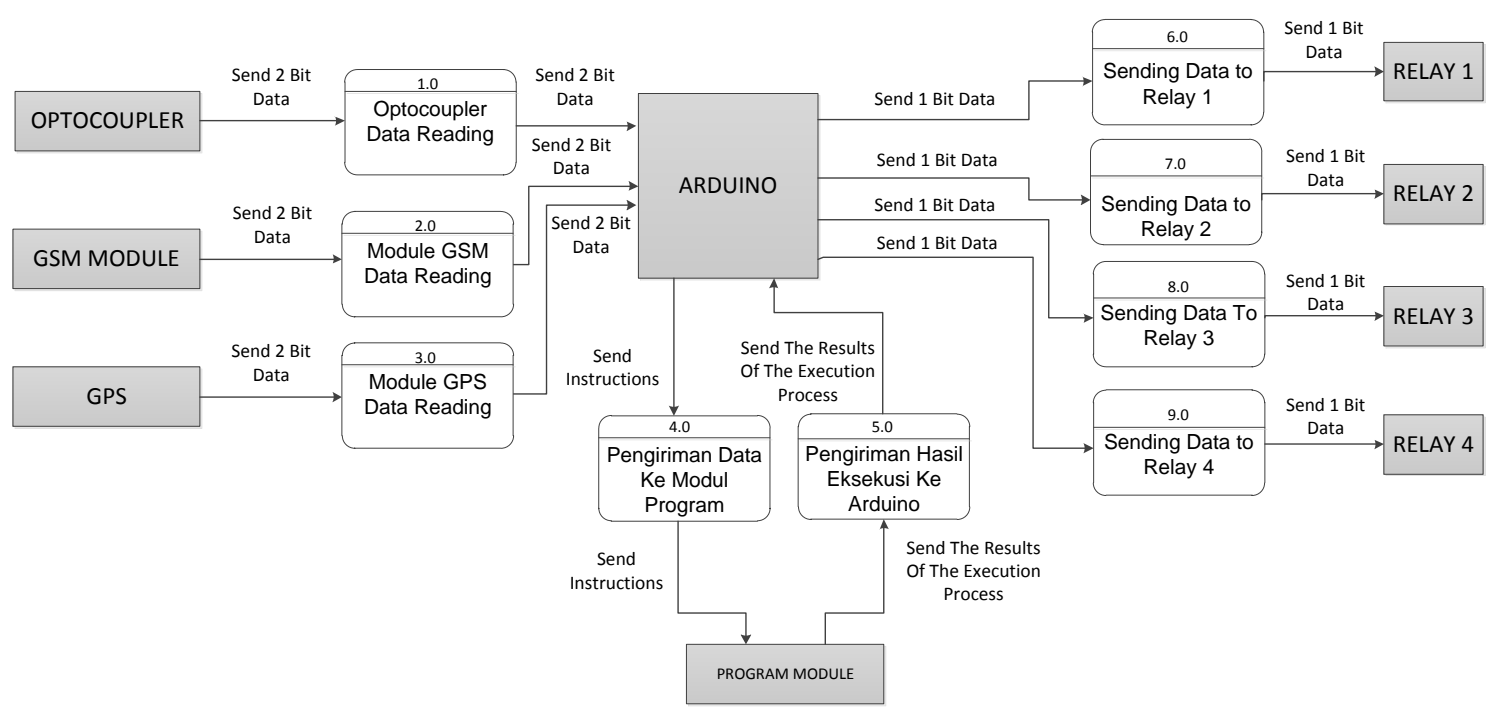

Figure 5. Data Flow Diagram 


\subsection{Principles of System Work}

In general, the system will work according to instructions in the form of data input on the Optocoupler sensor, GSM and GPS modules. Optocoupler sensors, GSM and GPS modules are located on motorized vehicles. If the motor speed exceeds $70 \mathrm{Km} /$ Hour, the system will send a speed notification SMS and will send the coordinates of the motorcyclist. And the system will automatically activate the relay as output to disable (On / Off) the motorcycle.

\section{CONCLUSION AND SUGESTION}

After testing the system, the following conclusions can be drawn:

1. By using the optocoupler sensor it can be easy to input the system so that the reading of the motor speed can be read properly.

2. GSM module can function properly, so that it can provide information in the form of SMS properly.

3. With the construction of a Sms Gateway Based Monitoring System for Parents Against the Use of Motorcycle Vehicles in Young Adolescents, so that parents can increase awareness of children in the use of motorbikes.

\section{FIGURES AND TABLE}

Pin Figure 6 below is a physical display of tools that will be used as a system to detect the speed of motorized vehicles.

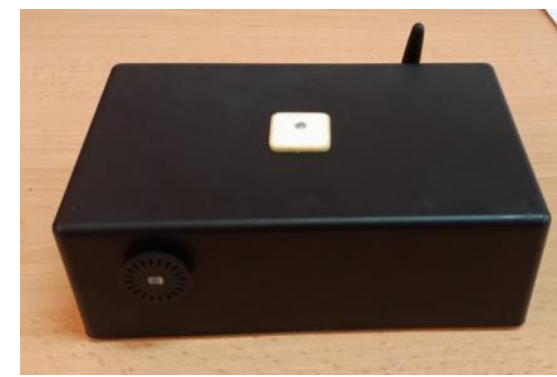

Figure 6: Physical Appearance of the Tool

In this system there are 2 test conditions that will be used as instructions, namely: If the speed is less than $70 \mathrm{Km} /$ Hour, then the status is Normal, Then If the speed is greater than $71 \mathrm{Km} /$ Hour, the vehicle status is fast and will send instructions in the form of the motorcyclist's coordinates.
Table 1. System Testing Table

\begin{tabular}{|c|c|c|c|}
\hline No & Speed & $\begin{array}{c}\text { Conditio } \\
\mathbf{n}\end{array}$ & Instructions \\
\hline 1. & $\begin{array}{c}<=70 \\
\mathrm{Km} / \text { Hour }\end{array}$ & Normal & - \\
\hline 2. & $\begin{array}{c}>=71 \\
\mathrm{Km} / \text { Hour }\end{array}$ & Fast & $\begin{array}{c}\text { Send } \\
\text { Coordinates }\end{array}$ \\
\hline
\end{tabular}

\section{ACKNOWLEDGMENT}

Based on research conducted by many parties involved, the research team thanked:

a. DIPA Directorate of Research and Community Service Directorate General of Higher Education, Directorate General of Research and Development Strengthening, Ministry of Research, Technology and Higher Education.

b. Padang Computer College Foundation and Putra Indonesia University YPTK Padang which have given time and opportunities in conducting research.

\section{REFERENCES}

Amirin, Tatang M. 1996. Main Systems Theory. PT. RajaGrafindo Persada: Jakarta.

Andrianto, Heri. 2008. Programming of ATMEGA AVR Microcontrollers16. Bandung: Informatics Publisher

Depari, Change. 1992. Learning Theory and Electronic Skills. Bandung: PT. Elex Media Computindo

Jogiyanto, HM. 1992. The Essence of Electronics. Jakarta: PT. Elex Media Computindo

Kusumadewi, Sri (2003), "Artificial Intelligence (Technique and its application)." Yogyakarta: Graha Science.

Malik, et al. 1997. Experimenting with a 8051 Microcontroller. Jakarta: PT. Gramedia.

R.Annamaria, Várkonyi-Kóczy (2010), "A Complexity Reduced Hybrid Autonomous Navigation Method for In-Door Robots

Pitowarno, Endra (2006), "Robotics: Design, Control, and Artificial Intelligence". Yogyakarta: Andi.

Suksmadana, Budi (2011), "Design of Building Robot Cars Using Fuzzy Logic to Navigate Based on AVR ATMega8535 Microcontroller"

Sutojo, T, Mulyanto, Edi, Suhartono, Vincent, Dr. (2011), "Artificial Intelligence". 